\title{
NÚMERO MÍNIMO DE COLHEITAS EM PEPINO HÍBRIDO ESTIMADO POR MEIO DO COEFICIENTE DE REPETIBILIDADE $\left(^{1}\right)$
}

\author{
ANTONIO ISMAEL INÁCIO CARDOSO $\left({ }^{2 *}\right)$
}

\begin{abstract}
RESUMO
O objetivo deste trabalho foi estimar o número mínimo de colheitas em experimento com a cultura do pepino. Foram analisados dados de um experimento onde avaliaram-se 14 híbridos de pepino japonês, no delineamento em blocos ao acaso, com quatro repetições e cinco plantas por parcela, conduzidas sob ambiente protegido. Foram efetuadas 32 colheitas, três colheitas por semana, por um período de 72 dias e estimados os coeficientes de repetibilidade, com base na análise de componentes principais para os caracteres produção de frutos por planta, em massa e número, total e comercial. Os resultados permitiram concluir que menos de nove colheitas foram suficientes para analisar as diferenças de produtividade entre os diferentes híbridos, com $95 \%$ de certeza de serem eleitos os mais produtivos.
\end{abstract}

Palavras-chave: Cucumis sativus L., produção, semanas de colheita.

\section{ABSTRACT \\ MINIMUM HARVEST NUMBER IN HYBRID CUCUMBER ESTIMATED BY REPEATABILITY COEFFICIENT}

The objective of this work was to estimate the minimum harvest number in experiments with cucumber. Data of an experiment comparing 14 japanese cucumber hybrids in the randomized block design, with four replications and five plants per plot, under protected cultivation, were analyzed. Thirtytwo harvestings were made, three harvests a week, during 72 days to estimate repeatability coefficient based on analysis of the principal components for number and weight of total and commercial fruits per plant. Results allowed to conclude that less than nine harvestings were enough to verify yield differences among hybrids, with $95 \%$ of probability to identify the highest yielding ones.

Key words: Cucumis sativus L., yield, harvesting week.

$\left.{ }^{1}\right)$ Recebido para publicação em 21 de setembro de 2005 e aceito em 4 de agosto de 2006.

$\left(^{2}\right)$ Departamento de Produção Vegetal, Faculdade de Ciências Agronômicas, Universidade Estadual Paulista, Caixa Postal 237, 18603-970 Botucatu (SP). * Autor correspondente. E-mail: ismaeldh@fca.unesp.br 


\section{INTRODUÇÃO}

Além do valor econômico e alimentar, o cultivo de cucurbitáceas tem grande importância social, na geração de empregos diretos e indiretos, pois demanda grande quantidade de mão-de-obra, desde o cultivo até a comercialização (LOPEs, 1991), sendo a cultura do pepino (Cucumis sativus L.) uma das que mais demandam mão-de-obra, pela necessidade de tutoramento, desbrotas e colheitas múltiplas (CAÑizares, 1998).

Por outro lado, essa grande necessidade de mão-de-obra tem sido um dos entraves na avaliação de experimentos com a cultura. Além disto, no melhoramento genético, geralmente, o número de tratamentos é muito grande, assim como o número de colheitas necessárias para se comparar os tratamentos, principalmente em cultivo sob ambiente protegido. A falta de informações sobre o período mínimo de colheitas para se avaliar um experimento pode levar o pesquisador a realizar um número de colheitas superior ao necessário para se diferenciar os tratamentos. Esse processo pode acarretar um desperdício na utilização de mão-de-obra e de recursos que estão cada vez mais restritos nos institutos de pesquisa.

Em culturas perenes, tem-se procurado definir o período mínimo de avaliações para comparação de genótipos em programas de melhoramento, os quais são de longo prazo. Nesses programas, não pode haver perda de tempo avaliando os genótipos além do necessário, assim como não se pode avaliar por um período muito pequeno que pode levar a erros na identificação dos genótipos superiores. Em cacau (Theobroma cacao L.), estimou-se que dois anos consecutivos de avaliações seria o suficiente (Dias e KageYama, 1998). Em umbu (Spondias tuberosa), SANTos (1999) estimou que três a quatro anos de coleta de dados são suficientes para a identificação dos indivíduos com maior produção de frutos, com $90 \%$ de precisão. Já em cajueiro-anão (Anacardium occidentale L.), três medições do caráter produção de castanha são suficientes durante o processo seletivo em programas de melhoramento genético (CAVALCANTI et al., 2000).

Normalmente, essas estimativas são realizadas utilizando-se o coeficiente de repetibilidade, pois com ele há possibilidade de se determinar quantas observações devem ser feitas em cada indivíduo, ou população, para que a discriminação, ou seleção fenotípica entre genótipos, seja feita com eficiência e um mínimo de custo e mãode-obra (Cruz e Regazzi, 1997). Portanto, o coeficiente de repetibilidade pode ser definido como a correlação entre as medidas de determinado caráter em um mesmo indivíduo, cujas avaliações foram repetidas no tempo ou no espaço. A estimativa desse coeficiente expressa a proporção da variância total que é explicada pelas variações proporcionadas pelo genótipo e pelas alterações permanentes atribuídas ao ambiente comum (CRUZ e RegAzZI, 1997).

Segundo FALCONER (1989), quando os valores de repetibilidade são elevados não há grande ganho em eficiência na seleção com grande número de medidas da característica. Já quando esse valor for baixo a seleção somente será eficiente com grande número de medições da característica ao longo do tempo ou espaço. Segundo Shimora et al. (2002), estimativas do coeficiente de repetibilidade acima de 0,5 podem ser consideradas razoáveis. O método mais tradicionalmente utilizado para estimativa do coeficiente de repetibilidade tem sido o da análise de variância. Entretanto, outros métodos utilizando componentes principais têm sido sugeridos (MANSOUR et al., 1981) e geralmente com maior precisão (CRUZ e ReGAZZI, 1997).

Em hortaliças, esse método foi utilizado para se estimar o período mínimo de colheitas em tomateiro (Lycopersicon esculentum Mill.), concluindo-se que sete colheitas são suficientes para analisar diferenças de produtividade entre acessos, com $95 \%$ de certeza de serem eleitos os mais produtivos (MARIM et al., 2002).

Em pepino não existe qualquer referência quanto ao número de colheitas a serem realizadas. Em trabalhos recentes publicados no Brasil observa-se uma variação de 30 a 80 dias no período de colheitas (CAÑizares e Goto, 1998 e 2002; CAÑIZARES et al., 2005; Cardoso, 2002; Cardoso e Silva, 2003; Costa et al., 2001; FERnANDES et al., 2002; Godoy et al., 2005; NomurA e Cardoso, 2000; Resende, 1999; Resende e Flori, 2003 e 2004; SEABRA Junior. et al., 2004).

Considerando-se a inexistência de relatos sobre o número de avaliações necessárias para os componentes da produção nos processos seletivos com a cultura de pepino, foi realizado o presente trabalho com o objetivo de estimar o número mínimo de colheitas que permitam a comparação de diferentes populações.

\section{MATERIAL E MÉTODOS}

Para realização deste estudo foram utilizados os dados de um experimento publicado por CARDOSO e Silva (2003), onde foram avaliados 14 híbridos de pepino japonês ('AF-1327', 'AF-1328', 'AF-1329', 'Hokuho', 'Hokushin', 'Hyuma', 'KH-705', 'Natsusuzumi', 'Nikkey', 'Rensei', 'Summer Green', 
'Top Green', 'Tsuyataro' e 'Yoshinari'), no outonoinverno, época de maior período de colheita. O experimento foi realizado na Fazenda Experimental São Manuel da FCA/UNESP, Campus de Botucatu, sob ambiente protegido.

O delineamento experimental foi em blocos ao acaso, com quatro repetições e cinco plantas por parcela. $\mathrm{O}$ espaçamento utilizado foi de $1,0 \mathrm{~m}$ entre fileiras e de 0,5 m entre plantas. A semeadura, em bandejas de poliestireno expandido de 128 células, foi realizada em 11/5/98 e o transplante em $1 .^{\circ} / 6 / 98$. A colheita foi iniciada 72 dias após a semeadura, mantendo-se uma periodicidade de três colheitas semanais. A última colheita ocorreu em 3/10/98. Para o cálculo do coeficiente de repetibilidade, foram consideradas as 32 colheitas realizadas.

No solo onde foi instalado o experimento havia teores de médios a altos para a maioria dos nutrientes (segundo tabela de classes de fertilidade do Boletim 100, RAIj et al., 1996), conforme os resultados da análise química: matéria orgânica $=10$ $\mathrm{g} \mathrm{dm}^{-3} ; \mathrm{P}_{\text {resina }}=59 \mathrm{mg} \mathrm{dm}^{-3} ; \mathrm{K}=2,0 \mathrm{mmol}_{\mathrm{c}} \mathrm{dm}^{-3} ; \mathrm{Ca}=$ $25 \mathrm{mmol}_{\mathrm{c}} \mathrm{dm}^{-3} ; \mathrm{Mg}=22 \mathrm{mmol}_{\mathrm{c}} \mathrm{dm}^{-3} ; \mathrm{CTC}=76 \mathrm{mmol}_{\mathrm{c}}$ $\mathrm{dm}^{-3}$; saturação por bases $=90 \% ; \mathrm{pH}\left(\mathrm{CaCl}_{2}\right)=6,8$. Por ocasião do preparo do solo, a adubação constou da aplicação de composto $\left(5 \mathrm{~L} \mathrm{~m}^{-2}\right)$, adubo formulado 4-14-8 (150 $\left.\mathrm{g} \mathrm{m}^{-2}\right)$ e nitrocálcio $\left(20 \mathrm{~g} \mathrm{~m}^{-2}\right)$. As adubações nitrogenadas, em cobertura, foram realizadas a cada 14 dias, colocando-se $5 \mathrm{~g}$ de nitrocálcio por planta.

As plantas foram conduzidas com tutoramento, eliminação de todas as brotações e flores até o quinto nó da haste principal, desbrota das ramas laterais (após o quinto nó da haste principal) entre a segunda e terceira folhas definitivas, e retirada do meristema apical da planta ao atingir a altura do arame (cerca de 1,8 $\mathrm{m}$ de altura).

Para estimativa do número mínimo de semanas de colheitas foram utilizadas as características relacionadas à produção de frutos por planta, em número e massa, total e comercial. Os frutos foram colhidos com cerca de $20 \mathrm{~cm}$ de comprimento e classificados em comerciais (sem deformações e retos) ou não.

Foram estimados os coeficientes de repetibilidade baseando-se na análise de componentes principais, assim como o coeficiente de determinação $\left(R^{2}\right)$ e o número mínimo de colheitas para avaliar diferenças de produtividade entre os híbridos, mantendo-se uma precisão de $95 \%$, segundo método descrito por CRUz e Regazzi (1997). As análises foram realizadas com o auxílio do programa computacional Genes (CRUZ, 2001).

\section{RESULTADOS E DISCUSSÃO}

Para todas as características foram obtidas estimativas do coeficiente de repetibilidade por meio da análise de componentes principais elevadas, variando de 0,87 a 0,94 o que reflete a estabilidade das características avaliadas nas sucessivas colheitas (Tabela 1). Por essa significativa regularidade na expressão do caráter de uma avaliação para a outra, é possível a predição do real valor dos híbridos com poucas avaliações e elevado nível de precisão, pois o coeficiente de determinação sempre foi superior a $98 \%$. Estes valores foram bem superiores aos obtidos por MARIM et al. (2002) em tomateiro, cujos valores de repetibilidade estimada a partir da análise de componentes principais variou de 0,16 a 0,37 e o coeficiente de determinação variou de $81 \%$ a $95 \%$. Segundo Shimora et al. (2002), estimativas do coeficiente de repetibilidade acima de 0,5 e do coeficiente de determinação acima de $80 \%$ podem ser consideradas razoáveis.

Tabela 1. Estimativas do coeficiente de repetibilidade estimado a partir da análise de componentes principais, com respectivos coeficientes de determinação e número mínimo de colheitas para os caracteres produção $(\mathrm{g})$ total (ProdTot) e comercial (ProdCom) e número de frutos total (NrFrTot) e comercial (NrFrCom) por planta. FCA/UNESP, São Manuel (SP)

\begin{tabular}{lcccc}
\hline & ProdTot & ProdCom & NrFrTot & NrFrCom \\
\hline$\rho$ & 0,94 & 0,93 & 0,89 & 0,87 \\
$R^{2}(\%)$ & 99,4 & 99,3 & 98,9 & 98,7 \\
N.C. $(95 \%)$ & 3,9 & 4,2 & 7,2 & 8,4 \\
N.C.Realizadas & 32 & 32 & 32 & 32 \\
\hline
\end{tabular}

$\rho=$ coeficiente de repetibilidade estimado a partir da análise de componentes principais.

$\mathrm{R}^{2}=$ coeficiente de determinação estimado a partir da análise de componentes principais.

N.C. $(95 \%)=$ número de colheitas suficientes para analisar diferenças de produtividade entre os genótipos avaliados, com 95\% de certeza de acerto. N.C.Realizadas $=$ número de colheitas realizadas.

As estimativas do número mínimo de colheitas suficientes para avaliar diferenças de produtividade variaram de 3,9 a 8,4 (Tabela1), podendo-se afirmar que a avaliação dos híbridos poderia ter sido realizada com nove colheitas, mantendo-se uma precisão de $95 \%$. Foram realizadas no experimento 32 colheitas, pois as condições ambientais eram desfavoráveis à incidência de doenças e as plantas se mantiveram saudáveis por grande período de tempo. Destaca-se, também, que no inverno o ciclo da cultura se alonga e o número de frutos colhidos em cada semana é inferior ao colhido no verão (CARDOSO, 2002; Cardoso e Silva, 2003). Portanto, o número de colheitas realizadas foi muito superior ao necessário para se diferenciar os tratamentos. 
A desvantagem em se colher nove vezes $(21$ dias) é a perda da estimativa do potencial de produção dos híbridos avaliados para as condições do experimento.

Em diversos experimentos com a cultura do pepino no Brasil publicados recentemente, há grande variação no tempo de colheita. SEABRA Junior. et al. (2004) e Nomura e CArdoso (2000) avaliaram a produção por 8,5 semanas no cultivo em Botucatu (SP). Já GoDOy et al. (2005) avaliaram por seis semanas em São Manuel (SP). Avaliando diferentes cultivares de pepino para processamento em Petrolina (PE), RESENDE e FLORI (2003 e 2004) realizaram colheita por um mês e RESENDE et al. (2002) por 40 dias. Resende (1999) comparou a produção de dez cultivares de pepino para conserva, em Porteirinha (MG), avaliando a produção por 40 dias. Fernandes et al. (2002) trabalhando no sistema hidropônico em Viçosa (MG) realizaram colheita por 45 dias. Já CAÑIZARES e GOTO (2002) compararam três métodos de enxertia avaliando produção por cinco semanas em Botucatu (SP). Em outro experimento comparando híbridos e portaenxertos, CAÑIZARES e Goto (1998) realizaram colheita por 80 dias. Ainda em Botucatu (SP), CostA et al. (2001) compararam diferentes teores de $\mathrm{K}$ em solução nutritiva realizando colheita por quatro semanas. Essa grande variação de condições ambientais e tempo de colheita pode ser uma explicação para resultados tão contrastantes, prejudicando a comparação de produção entre os diferentes relatos. Porém, em todos esses trabalhos citados, o período de colheita foi superior ao estimado como o mínimo necessário para a diferenciação dos tratamentos no presente trabalho, ou seja, cerca de 21 dias.

Certamente, os valores de período mínimo de colheitas não devem ser os mesmos para todas as condições. O coeficiente de repetibilidade é uma relação entre as variâncias genética e ambiental (CRUZ e Regazzi, 1997) e qualquer grande alteração ambiental, local e época de cultivo, por exemplo, pode alterar a estimativa da repetibilidade. Também devese destacar que foram avaliados apenas híbridos $F_{1}$, que tinham pouca, ou nenhuma, variabilidade genética. Talvez, a utilização de variedades de polinização aberta resultasse em aumento no número mínimo de colheitas para analisar diferenças de produtividade.

Os resultados obtidos permitem sugerir que em experimentos com a cultura do pepino apenas algumas colheitas são suficientes para a diferenciação das populações em avaliação, com redução de custos, mão-de-obra e tempo; para as condições em que foi realizado o experimento analisado, recomenda-se nove colheitas.

\section{CONCLUSÕES}

1. Houve elevada regularidade na expressão da produtividade em número e massa de frutos ao longo do período de colheitas.

2. Estimou-se que nove colheitas (21 dias) foram suficientes para avaliar as diferenças entre os tratamentos.

\section{REFERÊNCIAS}

CAÑIZARES, K.A.L. A cultura de pepino. In: GOTO, R.; TIVELLI, S.W. Produção de hortaliças em ambiente protegido: condições subtropicais. Fundação Editora da Unesp: São Paulo, 1998. p.195-223.

CAÑIZARES, K.A.L.; GOTO, R. Crescimento e produção de híbridos de pepino em função da enxertia. Horticultura Brasileira, Brasília, v.16, n.2, p.110-113, 1998.

CAÑIZARES, K.A.L.; GOTO, R. Comparação de métodos de enxertia em pepino. Horticultura Brasileira, Brasília, v.20, n.1, p.95-99, 2002.

CAÑIZARES, K.A.L.; RODRIGUES, J.D.; GOTO, R. VILLAS BÔAS, R.L. Influência da irrigação com água enriquecida com dióxido de carbono e da enxertia sobre o estado nutricional de plantas de pepino. Horticultura Brasileira, Brasília, v.23, n.1, p.9-14, 2005.

CARDOSO, A. I. I. Avaliação de cultivares de pepino tipo caipira sob ambiente protegido em duas épocas de semeadura. Bragantia, Campinas, v.61, n.1, p.43-48, 2002.

CARDOSO, A. I. I.; SILVA, N. Avaliação de híbridos de pepino tipo japonês sob ambiente protegido em duas épocas de cultivo. Horticultura Brasileira, Brasília, v.21, n.2, p.171-176, 2003.

CAVALCANTI, J.J.V.; PAIVA, J.R.; BARROS, L.M.; CRISÓSTOMO, J.R.; CORREAA, M.P.F. Repetibilidade de caracteres de produção e porte da planta em clones de cajueiroanão precoce. Pesquisa Agropecuária Brasileira, Brasília, v.35, n.4, p.773-777, 2000.

COSTA, P.C.; CAÑIZARES, K.A.L.; GOTO, R. Produção de pepino de plantas enxertadas cultivadas em soluções nutritivas com diferentes teores de potássio. Horticultura Brasileira, Brasília, v.19, n.3, p.339-341, 2001.

CRUZ, C.D. Genes: aplicativo computacional em genética e estatística. Viçosa: UFV. 2001. 648p.

CRUZ, C.D.; REGAZZI, A.J. Modelos biométricos aplicados ao melhoramento genético. Viçosa: UFV. 1997. 390p.

DIAS, L.A.S.; KAGEYAMA, P.Y. Repeatability and minimum harvest period of cacao (Theobroma cacao L.) in Southern Bahia. Euphytica, Wageningen, v.102, p.29-35, 1998. 
FALCONER, D.S. Introduction to quantitative genetics. $3^{\text {a }}$ ed. New York: John Wiley and Sons. 1989. 438p.

FERNANDES, A.A.; MARTINEZ, H.E.P.; OLIVEIRA, L.R. Produtividade, qualidade dos frutos e estado nutricional de plantas de pepino, cultivadas em hidroponia, em função das fontes de nutrientes. Horticultura Brasileira, Brasília, v.20, n.4, p.571-575, 2002.

GODOY, A.R.; OVIEDO, V.R.S.; CARDOSO, A.I.I. Análise endogâmica de uma população de pepino caipira. Horticultura Brasileira, Brasília, v.23, n.3, p.785-788, 2005.

LOPES, J.F. Palestra de abertura: I Simpósio brasileiro sobre cucurbitáceas. Horticultura Brasileira, Brasília, v.9, n.2, p.98-99, 1991.

MANSOUR, H.; NORDHEIM, E.V.; RUTLEDGE, J.J. Estimators of repeatability. Theoretical and Applied Genetics, v.60, n.3, p.151-156, 1981.

MARIM, B.G.;SILVA, D.J.H.; ABREU, F.B.; GUIMARÃES, M.A.; VALENTE, R.F.; ALVES, M.F. Número mínimo de colheitas em tomateiro estimado por meio do coeficiente de repetibilidade. Horticultura Brasileira, Brasília, v.20, n.2, Suplemento 2. CD-ROM, 2002. Trabalho apresentado no $42^{\circ}$ Congresso Brasileiro de Olericultura, 2002.

NOMURA, E.S.; CARDOSO, A.I.I. Redução da área foliar e o rendimento do pepino japonês. Scientia Agricola, Piracicaba, v.57, n.2, p.257-261, 2000.

RAIJ, B.Van; CANTARELLA, H.; QUAGGIO, J.A.; FURLANI, M.C. Recomendações de adubação e calagem para o Estado de São Paulo 2.ed. Campinas: Instituto Agronômico \& Fundação IAC, 1996. 285 p. (Boletim IAC, 100)
RESENDE, G. M. Produção de pepino para conserva na região norte de Minas Gerais. Horticultura Brasileira, Brasília, v.17, n.1, p.57-60, 1999.

RESENDE, G. M.; COSTA, N.D.; FLORI, J.E. Produtividade e qualidade de frutos de cultivares de pepino para conserva tipo "cornichon" no Vale do São Francisco. Horticultura Brasileira, Brasília, v.20, n.4, p.601-604, 2002.

RESENDE, G.M.; FLORI, J.E. Efeito de densidade de plantas na produtividade de cultivares de pepino para processamento tipo "cornichon". Pesquisa Agropecuária Brasileira, Brasília, v.38, n.11, p.1303-1307, 2003.

RESENDE, G.M.; FLORI, J.E. Rendimento e qualidade de cultivares de pepino para processamento em função do espaçamento de plantio. Horticultura Brasileira, Brasília, v.22, n.1, p.117-120, 2004.

SANTOS, C.A.F. In situ evaluation of fruit yield and estimation of repeatability coefficient for major fruit traits of umbu tree [Spondias tuberosa (Anacardiaceae)] in the semi-arid region of Brazil. Genetic Resources and Crop Evolution, v.46, n.5, p.455460, 1999.

SEABRA JÚNIOR, S.; GADUM, J.; CARDOSO, A.I.I. Produção de pepino em função da idade das mudas produzidas em recipientes com diferentes volumes de substrato. Horticultura Brasileira, Brasília, v.22, n.3, p.444-447, 2004.

SHIMOYA, A.; PEREIRA, A.V.; FERREIRA, R.P.; CRUZ, C.D.; CARNEIRO, P.C.S. Repetibilidade de características forrageiras do capim elefante. Scientia Agricola, Piracicaba, v.59, n.2, p.227-234, 2002. 